\title{
Essential thrombocythemia presenting as digital ischemia
}

\author{
Md. Nazmul Hasan, Md. Abdur Rahim, Quazi Mamtaz Uddin Ahmed, Md. Syedul Islam, \\ Md. Atikur Rahman and Md. Shamim
}

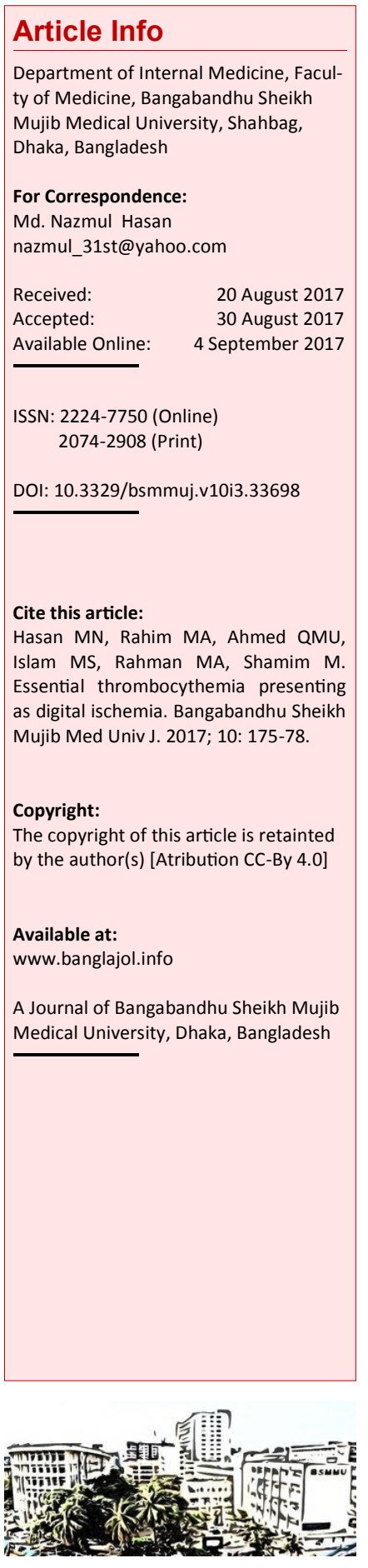

\section{Abstract}

Essential thrombocythemia is a myeloproliferative disease and is characterized by increased production of platelet and increased megakaryocytes in the bone marrow. Though platelets are high in number but may not function normally and can cause hyperviscosity syndrome and blockage of the blood vessels and other complications. Here, we report two cases of essential thrombocythemia, presented with pain in hands and feet and one with digital infarction. Both the patients had headache and vertigo.

\section{Introduction}

Myeloproliferative disorder includes policythemia rubra vera, primary myelofibrosis and essential thrombocythemia. 1 Essential thrombocythemia is a diagnosis of exclusion that needs to deduct both reactive thrombocytosis and other myeloprolifeartive disorder.2 Life expectancy in essential thrombocythemia is normal but mortality increases if associated comorbidities are present. 3 Rarely, some patient develops acute myeloid leukemia and myelofibrosis.

\section{Case Reports}

\section{Case 1}

A 45 year old woman was admitted in the Department with pain and discoloration of the left hand and both feet for two months and blackening of left fourth toe for 14 days. She had redness and pain in the feet which is persistent and not aggravated by exposure to cold. She was also suffering from an intermittent headache and vertigo. She had a spontaneous miscarriage at the first trimester and was taking oral contraceptive pill for 5 years. Physical general examination revealed, she was mildly anemic, pulse was 100 beat per min and all peripheral pulses were present, blood pressure was $120 / 80 \mathrm{~mm}$ of $\mathrm{Hg}$, respiratory rate was 14 breaths per min and on examination of the limbs, there was bluish discoloration of fingers of left hand and all toes, reddish coloration of left palm of hands and sole of feet, raised temperature, tender and dry gangrene in left $4^{\text {th }}$ toe and levedo reticularis over sole of the feet (Figure 1). Systemic examination revealed normal. Investigations revealed FBC: Hemoglobin- $11.7 \mathrm{gm} / \mathrm{dL}$, ESR- $35 \mathrm{~mm} 1^{\text {st }}$ hour, RBC- $4.15 \times 10^{12} / \mathrm{L}$, platelet- 3,500×109/L, WBC count revealed total count- $17.36 \times 10^{9} / \mathrm{L}$, neutrophil- $71 \%$, lymphocyte- $24 \%$, monocyte$4 \%$, eosinophil- $1 \%$, basophil- $0 \%$, PCV- $0.361 / 1$, MCV-86.3 fl, MCH- 28.2 pg, MCHC- 32.7 g/dL, RDW(CV)- $15.3 \%$ (Table I).

The peripheral blood film demonstrated: RBCanisocytosis and anisochromia, WBC- mature with above distribution, platelet- markedly increased in number and plenty of platelet clumps and the comment was features suggestive of essential thrombocythemia (Figure 2).

Bone marrow trephine biopsy revealed hypercellular marrow with increased M:E ratio with active erythropoesis and granulopoesis and grossly hyperactive with giant megakaryocytes with hyperlobulated nuclei, features consistent with essential throbocythemia (Figure 2).

The liver function, renal function, urine $\mathrm{R} / \mathrm{M}$ / $\mathrm{E}$ and electrolyte were normal. C-reactive protein was $3 \mathrm{mg} / \mathrm{dL}$. Prothrombin time was $13 \mathrm{sec}$, activated partial thromboplastin time was 33 sec. The ANA, anti-phospholipid antibody, C-ANCA and P-ANCA, anti-CCP, $\mathrm{HBs}-\mathrm{Ag}$, anti-HCV all were negative. USG of abdomen and duplex scan of the both lower limbs were normal. JAK-2 V617F was negative. Her condition had initially improved after treatment with aspirin, hydroxyurea and antibiotic to treat super added infection in the hand. But it later was refractory to medical treatment and platelet counts remained 28 lacs and digital infarction progressed despite adequate dose titration of the drugs for two weeks. So, she underwent one episode of plasmapharesis and her platelet count and 


\begin{tabular}{|c|c|c|c|}
\hline \multicolumn{4}{|c|}{ Table I } \\
\hline \multicolumn{4}{|c|}{ Blood picture of two cases } \\
\hline & Case 1 & Case 2 & $\begin{array}{r}\text { Reference } \\
\text { range }\end{array}$ \\
\hline Hemoglobin $(\mathrm{g} / \mathrm{dL})$ & 11.7 & 15 & $13.5-17.5$ \\
\hline ESR (mm 1st hour) & 35 & 30 & $0-22$ \\
\hline RBC (million cells $/ \mu \mathrm{L}$ ) & 4.15 & 6.48 & $6.7-6.1$ \\
\hline WBC (x109/L) & 17.36 & 18.36 & $4-11$ \\
\hline Neutrophil (\%) & 71 & 51 & $40-80$ \\
\hline Lymphocyte (\%) & 24 & 31 & $20-40$ \\
\hline Monocyte (\%) & 4 & 4 & $2-10$ \\
\hline Eosinophil (\%) & 1 & 8 & $1-6$ \\
\hline Basophil (\%) & 0 & 0 & $<1-2$ \\
\hline Platelet (x109/L) & 3,500 & 1,700 & $150-400$ \\
\hline PCV & 0.36 & 0.46 & $0.36-0.48$ \\
\hline MCV (fL/red cell) & 86.3 & 72 & $80-96$ \\
\hline MCH (pg/cell) & 28.2 & 23.2 & $27-33$ \\
\hline $\mathrm{MCHC}(\mathrm{g} / \mathrm{dL})$ & 32.7 & 32 & $33-36$ \\
\hline RDW (CV) (\%) & 15.3 & 17 & $11.5-14.5$ \\
\hline
\end{tabular}

digital ischemia has improved. After that, she was on hydroxyurea and aspirin and followed-up.

\section{Case 2}

A 38 year old woman was admitted in the Department with pain and discoloration of fingers of the both hands and burning sensation, all those symptoms became worse for last 10 days. On general physical examination, she had pulse- 88 beats per $\min$ and all peripheral pulses were present. The blood pressure was $110 / 80 \mathrm{~mm}$ of $\mathrm{Hg}$, respiratory rate was 14 breaths per min and there was bluish discoloration of all fingers with blackening without any definite demarcation with

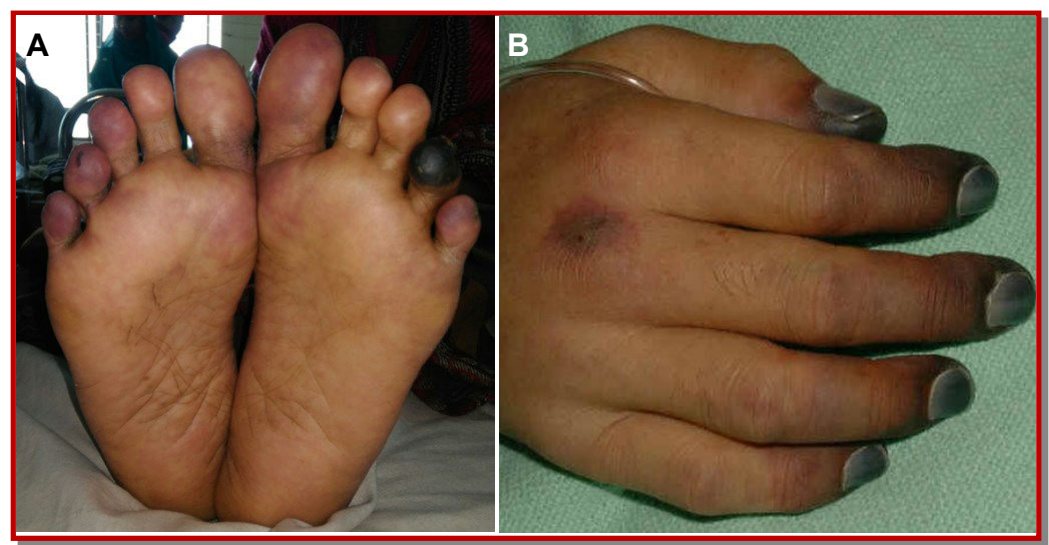

Figure 1: Picture of feet showing redness, bluish discoloration and gangrene of the $4^{\text {th }}$ toe (case 1, A); Picture of the right hand showing bluish discoloration with blackening of the fingers (case $2, \mathrm{~B}$ ) the normal tissue (Figure 1). There was thyromegaly without retrosternal extension and systemic examination revealed normal findings. The investigations showed FBC: Hemoglobin- 15 gm/dL, ESR- $30 \mathrm{~mm}$ $1^{\text {st }}$ hour, RBC- $6.48 \times 10^{12} / \mathrm{L}$, platelet- $1,700 \times 10^{9} / \mathrm{L}$, WBC- $18.36 \times 10^{9} / \mathrm{L}$, neutrophil- 51\%, lymphocyte$31 \%$, monocyte- $4 \%$, eosinophil- $8 \%$, basophil- $0 \%$, PCV- 0.46, MCV- 72 fl, MCH- 23.2 pg, MCHC- 32 g/ $\mathrm{dL}, \mathrm{RDW}(\mathrm{CV})-17 \%$. The peripheral blood film showed RBC- microcytic and hypochromic, WBCincreasd and mature with above distribution, platelet- markedly increase in numbers and the comments were microcytic hypochromic anemia, leucocytosis and thrombocytosis (Figure 2).

Bone marrow study revealed normocellular marrow with normal M:E ratio with active and normoblastic erythropoesis and granulopoesis and increased number of multilobulated megakaryocyte with clumping. All this features were consistent with essential throbocythemia. The ultrasonography of thyroid showed diffuse enlargement without retro-sternal extension. The thyroid function test was normal. The liver function test, renal function test, urine for routine and microscopic examination and electrolyte were normal. The Creactive protein was $3.48 \mathrm{mg} / \mathrm{dL}$, prothrombin time was $16 \mathrm{sec}$, activated partial thromboplastin time was $39 \mathrm{sec}$. The auto-antibodies like ANA, anti-phospholipid antibody, C-ANCA and PANCA, anti-CCP and HBsAg, anti-HCV m, all were negative. The ultrasonography of abdomen and duplex scan of the both lower limbs were normal. JAK-2 V617F was negative. She was treated with hydroxyurea and aspirin and has significant improvement of the symptoms and was discharged with advice for follow-up.

\section{Discussion}

Thrombocytosis is defined as, when platelet count is more than six thousand per mL. 5 It can be reactive (secondary) or as a part of myeloproliferative disorder. The secondary thrombocytosis is caused by increased amount of thrombopoeitin, cytokines or catecholamine which are synthesized in many conditions like inflammatory, infectious, stressful or neoplastic conditions. 6 The clonal thrombocytosis is produced in myeloproliferative disorders and myelodysplastic syndrome with 5q-deletion syndrome. 7 In case of both patients, we reported here, was treated by different physicians as a case of migraine and connective tissue disease as a cause of digital infarction. In the first case, blood counts were done without platelet count and it was also refractory to medical management needing plateletpharesis. So, these cases are reported because this is not a common disease and demonstrate how routine examination of complete blood picture is so 


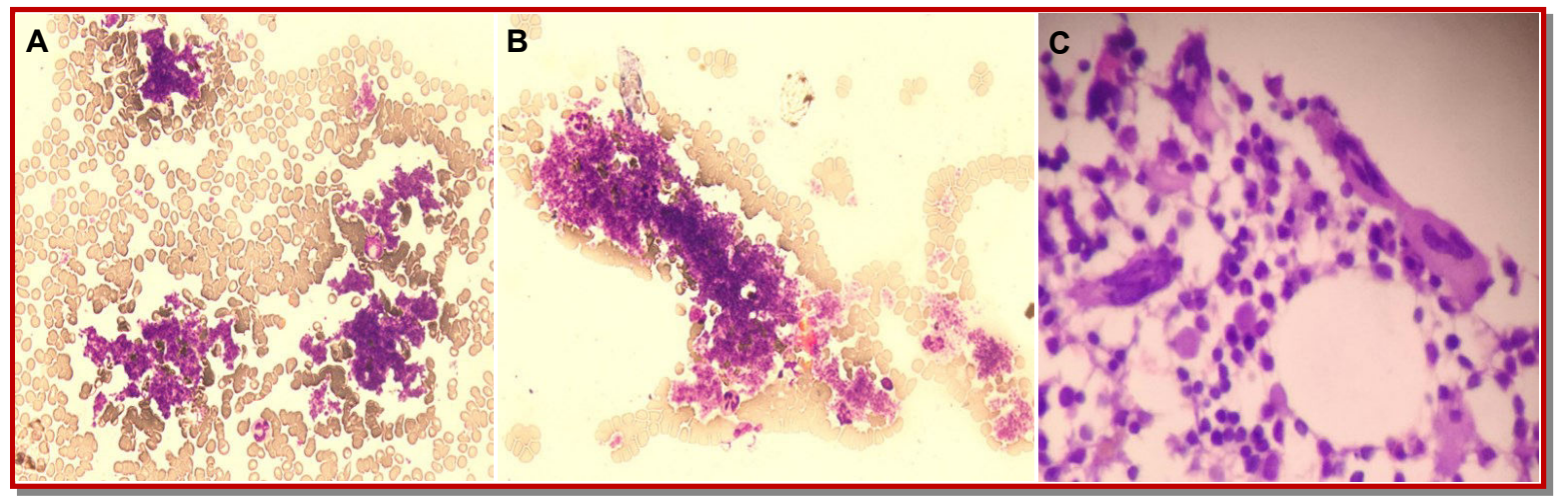

Figure 2: Peripheral blood film showing increased platelet with clumping (case 1, A); Peripheral blood film showing increase platelet with clumping (case 1, B); Picture of bone marrow trephine biopsy showing giant megakaryocyte with multilobulated nuclei (case 2, C)

important.

Essential thrombocythemia is a rare myeloproliferative disease and the incidence is $0.4-2.5$ per 100,000 per year. 8 It has female preponderance and usually occurs in the fifth or sixth decade of life.9 Te JAK2 V617F mutation is positive in $50-60 \%$ of cases.10 Essential thrombocythemia presents with hemorrhagic complications, due to platelet dysfunction, or thrombotic disorders like stroke, myocardial infarction, venous thrombosis, and digital ischemia. Thrombotic event is frequent when JAK2 V617F mutation is present. 10 Most of the time, the platelet count is elevated above $1,000 \times 10^{9} / \mathrm{L}$ but the studies agree a median level of around $800 \times 10^{9} /$ L.11 Lower levels are usually attributed to inflammation or tissue necrosis.

Our first patient presented with the persistent redness and pain of the feet and hands which suggest erythromelagia and the second case presented with triphasic white, blue and red color change of Raynaud's and in both cases features of digital ischemia were present. The erythromelalgia is the more common presentation in essential thrombocythemia. $\underline{12}$ The erythromelagia is characterized by redness and painful burning sensation of the extremities with symptoms aggravated by heat or exercise and relieved by cold. Though our first patient could not mention any definite aggravating factors. In a retrospective study of 268 essential thrombocythemia patients, 15 of them had features of erythromelagia and only one patient had Raynaud's phenomenon. 12 The underlying pathology of erythromelagia is thought to be occlusion of the microcirculation by platelets, which is also considered as a mechanism in essential thrombocythemia associated Raynaud's. $\underline{13}$ We reached the diagnosis by excluding the all causes of reactive thrombocythemia by appropriate investigations. We used the revised diagnostic criteria for essential thrombocythemia that were proposed in 2005. 13 As there is no specific molecular marker, the diagnosis of essential thrombocythemia can only be settled after a step-by-step elimination of the other clinical situations associated with a protracted elevation of the platelet number. $\underline{14}$ Although we performed cytogenic studies and JAK2 V617F were negative but our cases satisfy the revised diagnostic criteria of essential thrombocythemia. We treated our patients with aspirin and hydroxyurea, but the first case required one episode of plateletpharesis and consulted General Surgery Department for management of the gangrene. Follow-up of blood complete picture shows that the platelet count was reduced and patient showed much improvement in both the cases. Hydroxyurea is effective in preven-ting thrombosis in high-risk patients with essential thrombocythemia. 15 The new agent anagrelide has recently been introduced for the treatment of essential thrombocythemia. However, recent studies showed that anagrelide is not significantly more effective than traditionally used hydroxyurea. $\underline{6}$

\section{Conclusion}

Digital ischemia is rare manifestation of the essential thrombocythemia. With the help of routine complete blood count, bone marrow study and by the exclusion of other causes of thrombocytosis diagnosis can be made. The management is largely based on cytoreductive therapy with aspirin where indicated and plateletpharesis is needed in few cases only.

\section{References}

1. Tefferi A. The Philadelphia chromosome negative chronic myeloproliferative disorders: A practical overview. Mayo Clin Proc. 1998; 73: 1177.

2. Harrison CN. Current trends in essential thrombocythaemia. Br J Haematol. 2002; 117: 796.

3. Passamonti F, Rumi E, Pungolino E, Malabarba L, Bertazzoni P, Valentini M, Orlandi E, Arcaini L, Brusamolino E, Pascutto C, Cazzola M, Morra 
E, Lazzarino M. Life expectancy and prognostic factors for survival in patients with polycythemia vera and essential thrombocythemia. Am J Med. 2004; 117: 755-61.

4. Fenaux P, Simon M, Caulier MT, Lai JL, Goudemand J, Bauters F. Clinical course of essential Thrombocythemia in 147 cases. Cancer 1990; 66: 549-56.

5. Harrison CN, Campbell PJ, Buck G, Wheatley K, et al. Hydroxyurea compared with anagrelide in highrisk essential thrombocythemia. N Engl J Med. 2005; 353: 33-45.

6. List AF, Avery A, Doll DC. Sandberg. Myelodysplastic syndromes. In: Wintrobe's clinical hematology. Greer JP, Foerster J, Lukens JN, Rodgers GM, Paraskevas F, Glader B (eds). 11th ed. Philadelphia, Lippincott Williams and Wilkins, 2004, pp 2207-34.

7. Schafer AI. Thrombocytosis. N Engl J Med. 2004; 350: 1211-19.

8. Rozman C, Giralt M, Feliu E, Rubio D, Cortés MT Life expectancy of patients with chronic nonleukemic myeloproliferative disorders. Cancer 1991; 67: 2658-63.

9. Mesa RA, Silverstein MN, Jacobsen SJ, Wollan PC, Tefferi A. Population based incidence and survival figures in essential thrombocythaemia and agnogenic myeloid metaplasia: An Olmsted county study, 1976-1995. Am J Hematol. 1999; 61: 10-15.
10. Takata Y, Seki R, Kanajii T, Nohara M, Koteda S, Kawaguchi K, Nomura K, Nakamura T, Morishige S, Oku E, Osaki K, Hashiguchi E, Mouri F, Yoshimoto K, Nagafuji K, Okamura T. Association between thromboembolic events and the JAK2 V617F mutation in myeloproliferative neoplasms. Kurume Med J. 2014; 60: 89-97.

11. Carobbio A, Finazzi G, Antonioli E, Guglielmelli P, Vannucchi AM, Delaini F, Guerini V, Ruggeri M, Rodeghiero F, Rambaldi A, Barbui T. Trombocytosis and leukocytosis interaction in vascular complications of essential thrombocythemia. Blood 2008; 112: 3135-37.

12. Itin PH, Winkelmann RK. Cutaneous manifestations in patients with essential thrombocythemia. J Am Acad Dermatol. 1991; 24: 59-63.

13. Greer JP, Foerster J, Lukens JN, Rodgers GM, Paraskevas F. Wintrobe's Clinical hematology. 11th ed. Philadelphia, Lippincott Williams and Wilkins, 2004, pp 2207-34.

14. Campell PJ, Green AR. Management of polycythemia vera and essential thrombocythemia. Hematol Am Soc Hematol Educ Program. 2005: 201-08.

15. Cortelazzo MS, Finazzi MG, Ruggeri MM, Vestri MO, Galli MM, Rodeghiero MF, Barbui MT. Hydroxyurea for patients with essential thrombocythemia and a high-risk of thrombosis. N Engl J Med. 1995; 332: 1132-37. 